\title{
Changes in Allometric Attributes and Biomass of Forests and Woodlands across an Altitudinal and Rainfall Gradient: What Are the Implications of Increasing Seasonality due to Anthropogenic Climate Change?
}

\author{
John T. Hunter \\ School of Behavioral, Cognitive and Social Sciences, University of New England, Armidale, NSW 2351, Australia \\ Correspondence should be addressed to John T. Hunter; jhunter8@bigpond.com
}

Received 23 February 2015; Accepted 2 April 2015

Academic Editor: Béla Tóthmérész

Copyright (C) 2015 John T. Hunter. This is an open access article distributed under the Creative Commons Attribution License, which permits unrestricted use, distribution, and reproduction in any medium, provided the original work is properly cited.

Canonical correspondence analysis and linear regressions were used to relate height, diameter, and dispersion measurements of 36,380 stems from 197 species recorded in 2,341 plots against both climatic and landscape variables. Above ground biomass increased in wetter and cooler locations that ameliorate the seasonal rainfall deficits. Taller and greater diameter trees with lower wood densities occur at higher altitudes. Differences between locations are based on a change in the composition of species rather than a change in the allometric properties within a species. The results support the hydraulic limitation and species packing hypotheses. These interrelationships may be affected by the interactions of fire frequency and drought which are a common feature of much of the study area. Under current climate change scenarios it is likely that there will be a reduction in above ground biomass, the number of stems per hectare, average height, average diameter, and basal area due to increasing seasonality of rainfall, temperatures, and the intensity and frequency of fires. The largest of trees are likely to be removed early due to their inability to cope with increased drought stress. The results suggest a marked reduction in carbon storage will occur across the study region in eastern Australia.

\section{Introduction}

Central to functional ecology is the ability to link changes in species traits to ecosystem processes [1]. The allometric traits of trees determine the capture of resources, affect the transport of those resources throughout the plant, and also affect resistance to mechanical damage. These traits are indicative of survival versus growth life history trade-offs [2-4]. Differences in allometry potentially structure coexistence between species [5]. However, the way in which these allometric traits change across environmental gradients has been poorly investigated in any detail across diverse habitats $[4,6]$. Cumulatively, allometric traits also structure the above ground biomass obtainable by a species and collectively the community in which it occurs. Therefore, knowledge of the spatial patterns of allometric traits allows understanding of changes in ecosystem function $[2,7,8]$.
Altitude is an easily measurable surrogate for a number of environmental factors and thus is often used to measure change within assemblages including structure, composition, and species traits. Altitude has been shown to correlate with variation in tree allometric properties due to the concomitant changes in rainfall, air, and soil temperatures and differences in nutrient availability and soil chemistry [9]. Increasing altitude not only affects climate but also is associated with a decrease in atmospheric pressure which directly affects photosynthesis [10]. Biomass has been found to peak in cool wet environments associated with higher altitudes [9]. In contrast, Larjavaara and Muller-Landau [8] found above ground biomass declined with increasing altitude. Culmsee et al. [9] noted a number of changes in forest structure including a decrease in tree height with increasing altitude. Lines et al. [4] while investigating intra- and interspecific changes in allometric traits with altitude discovered that 
taller species were associated with cooler higher altitude regions. Conversely, within a species, individuals were taller in warmer low altitudes [4]. Slik et al. [11] attributed stunting in height with altitude to lower growth and productivity at colder temperatures.

Slik et al. [11] found that both basal area and above ground biomass were positively correlated with annual rainfall but negatively with increasing rainfall seasonality. Within moist and wet tropical forests of the Amazon Basin above ground biomass was positively correlated with increasing precipitation of the driest quarter [12]. Keith et al. [13] found a peak in biomass in wet and cool regions. In an intercontinental study Banin et al. [3] correlated higher above ground biomass with seasonal climates where rainfall in the wettest period was highest. They suggested that higher rainfall within the wettest period allowed the soil profile to remain moist through the drier season and that the seasonal rainfall regime reduced hydraulic constraints on trees allowing them to achieve greater biomass [3]. Culmsee et al. [9] while investigating a number of forest types showed that neither temperature nor precipitation of the driest quarter was consistently correlated with above ground biomass suggesting that only in relatively dry systems is precipitation a limiting factor. Support for the limiting role of precipitation on biomass in arid and semiarid systems was also found.

Above ground biomass accumulation and basal area are influenced by the presence of large diameter trees within a site [14, 15]. This led Midgley et al. [14] to propose the packing hypothesis which states that plot basal area and biomass will be strongly related to size of the largest individual because larger individuals pack space more efficiently. Stegen et al. [6] argued that if the largest tree was strongly correlated with biomass it is fundamentally through the influence of climate on the maximum individual tree mass. In open forests the abundance of trees may be below their theoretical maximum density and their canopies more open due to resource limitation allowing small individuals more access to resources, thus affecting the size distribution of stems and their density across the community [16].

Most investigations into above ground biomass have been carried out within tropical closed forests (e.g., $[3,7,9,11,17-$ 20]) with investigations into these attributes within temperate woodlands being infrequent $[5,13,21]$. Tropical closed forest studies have largely focused on competition for light being a major limiting factor structuring allometric attributes of species and associated above ground biomass. Woodlands and forests away from tropical regions will have reduced light due to the more oblique nature of solar radiation; however, they are still likely to be decoupled from the constraints of limited light. Thus other environmentally limiting factors are likely to be of importance $[3,4,16]$.

Aiba and Nakashizuka [5] argued that relationships between tree properties and ecology are sensitive to which species are studied and argued that the number of species needs to be large enough to allow for a general understanding of patterns at the community level. Most above ground biomass studies have been based on correlations restricted to single forest types, limited in geographic extent and with few samples $[4,6]$. Lines et al. [4] also argued that many

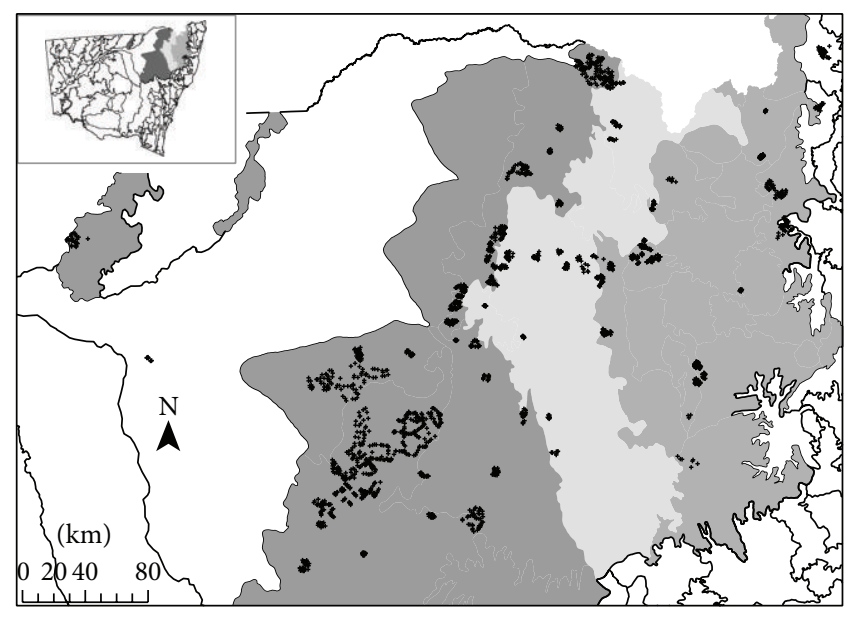

Bioregion name

Brigalow Belt South

Bioregion

Nandewar

New England Tablelands

FIGURE 1: Location of the 2,341 allometric survey sites within northeastern New South Wales, Australia.

studies have underused computation methods that effectively separate covarying correlates.

Using an extensive dataset of many species collected across a large regional area I attempt to assess the major factors influencing tree AGB and associated allometric properties. What factors are associated with AGB within temperate forests and woodlands within a semiarid to temperate summer dominant rainfall zone is investigated. It is assessed whether altitude, temperature, and rainfall are the major influences as has been shown within studies of tropical forests worldwide. Furthermore it is investigated whether there is evidence for the packing hypothesis of Midgley et al. [14] and whether the relationships between tree height and altitude exist within eastern Australian woodlands and forests. The implications of the results are discussed in terms of predicted anthropogenic climate change within the region.

\section{Methods}

2.1. Study Area. The study was undertaken primarily within the New England Tablelands, Nandewar, and Brigalow Belt South Bioregions [22] within New South Wales (Figure 1; approximately 8 million hectares). In the region of investigation 2,341 sites were placed almost exclusively within the national reserve system (national parks, nature reserves, state conservation areas, community conservation areas, and aboriginal areas) and on privately managed reserves (Nature Conservation Trust Agreements and Voluntary Conservation Agreements). Such locations where chosen in order to minimise structural disturbance factors and different management objectives. Seventy-seven private and public conservation areas were surveyed and sites placed randomly within prechosen strata. These strata were generally based on rock type, altitude, aspect, and landform position allowing for 
replication within each conservation area. No locations were under grazing or any other primary production and the focus of land management was conservation (maintain or improve current natural condition). Sample sites were chosen for minimal postcolonisation anthropogenic disturbance. Any locations with obvious overstorey removal were excluded from the primary dataset.

Altitudes ranged from $122 \mathrm{~m}$ above sea level at Narran Lakes $\left(30^{\circ} 31^{\prime}, 151^{\circ} 30^{\prime}\right)$ to $1,371 \mathrm{~m}$ above sea level at Butterleaf northeast of Glen Innes $\left(29^{\circ} 30^{\prime}, 152^{\circ} 00^{\prime}\right)$. The study area is dominated by the Dividing Range which runs southwest along the eastern edge of the region with an associated high altitude tableland area (over $800 \mathrm{~m}$ a.s.l). Altitudes fall to the west levelling to open plains. Some isolated high altitude areas occur in western locations away from the main range $(\mathrm{Mt}$ Kaputar 1,300 m; Warrumbungle Range 1,100 m). The most northerly sites were within the Yelarbon area $\left(28^{\circ} 42^{\prime}, 140^{\circ} 47^{\prime}\right)$ and the most southerly nearby Biddon $\left(31^{\circ} 38^{\prime}, 148^{\circ} 48^{\prime}\right)$. Annual mean temperatures range from $11.7^{\circ} \mathrm{C}$ to $20.5^{\circ} \mathrm{C}$ and the annual mean rainfall from $422 \mathrm{~mm}$ to $1,140 \mathrm{~mm}$. Around $60 \%$ of annual rainfall occurs from November to March; thus rainfall is seasonal with a marked summer peak and dry winters. Seasonality increases from south to north. Rainfall is proportionately higher along the far east of the Dividing Range as it receives additional orographic precipitation while the western areas are increasingly within rain shadow. Generally taller forests and closed forests occur along the eastern escarpment with open forests and woodlands dominating in intermediate altitudes and open woodlands and shrublands common within the extreme western and lower altitude locations.

2.2. Site Survey. A random tree with a minimum diameter at breast height $(130 \mathrm{~cm})(\mathrm{DBH})$ of $10 \mathrm{~cm}$ was chosen as a central tree at each location. From this tree 15 of the closest trees of over $10 \mathrm{~cm} \mathrm{DBH}(130 \mathrm{~cm})$ were recorded $(16$ trees inclusive of the central stem). The size of these tree sites was unbounded and dependent on the distance to the furthest tree recorded. For each tree the identity of the species and distance to the first tree (meters) were recorded. At each location information was gathered on location and altitude with reference to Geographical Positioning System (GPS; Garman Map 62s; Garmin International, Olathe, KA, USA) along with physiography, soil drainage, and depth. Sites were surveyed over a period of six years (2006 to 2012). Nomenclature follows that given by PlantNET (http://plantnet.rbgsyd.nsw.gov.au/ accessed December 2012). An average of all stem distances from the central stem was used for calculations of above ground biomass in addition to that provided by the furthest stem as a form of standardisation. To assess the effect of clumping, the evenness of the distribution of distances within each stem plot was calculated using PAST [23]. Evenness essentially measures the dispersion of stems. If all stems have the same distance from the central stem then a perfectly even score would result $(+1)$; however if stems are dispersed unevenly (most toward the centre a few further away or vice versa) within the stem plot the evenness score will be much reduced (towards 0 ). The most uneven plots were excluded from the analysis. Evenness was an attribute that was tested in its own right and in combination with the AGB scores.

2.3. Explanatory Variables. The above ground biomass (AGB) of all species was calculated based on the dry forest equation provided by Chave et al. [18],

$$
\mathrm{AGB}=\exp \left(-2.187+0.916 \times \ln \left(\rho D^{2} H\right)\right)
$$

where $\rho$ is the oven-dry wood specific gravity (grams per cubic meter), $D$ is the diameter (in centimeters) of the tree at breast height $(130 \mathrm{~cm})$, and $H$ is tree height (in meters). The resulting estimate of AGB is in kilograms [18]. Wood density was derived from the average of available sources for each species ([24]; http://www.timberanswers.com/ accessed February 2013). Where only moist wood density was available the figure was converted to the oven-dry equivalent using the conversion supplied by Chave et al. [19] where $r$ is the radius,

$$
\rho=0.872 \times r_{12}
$$

Wood density is considered to be a taxonomically conservative trait $[2,3,6,17,25]$; thus for species where this trait was unavailable the average from the species closest relatives was assigned. AGB was calculated for each individual tree. The above ground biomass scores were then extrapolated to kilograms per hectare based on the size of the original plot and the combined scores of all individual trees. A figure for the combined stem $\mathrm{m}^{2}$ per hectare was calculated based on the area of the stem plot raised to the size of a hectare.

AMUCLIM 6.1.1 [26] was used to model 35 bioclimatic parameters based on the climate variables maximum temperature, minimum temperature, rainfall, solar radiation, and pan evaporation. The climatic parameters produced are annual mean temperature (AMT); mean diurnal range (MDR); isothermality; maximum temperature of the warmest period (MaTWeP); minimum temperature of the coldest period (MTCP); temperature annual range (TAR); mean temperature of wettest quarter (MeTWeQ); mean temperature of driest quarter (MeTDQ); mean temperature of warmest quarter $(\mathrm{MeTWaQ})$; mean temperature of coldest quarter (MeTCQ); annual precipitation (AP); precipitation of the wettest period (PWP); precipitation of driest period (PDP); precipitation seasonality (PS); precipitation of wettest quarter (PWQ); precipitation of driest quarter (PDQ); precipitation of warmest quarter (PWaQ); precipitation of coldest quarter (PCQ); annual mean radiation (AMR); highest period of radiation (HPR); lowest period radiation (LPR); radiation seasonality (RS); radiation of wettest quarter (RWeQ); radiation of driest quarter (RDQ); radiation of warmest quarter $(\mathrm{RWaQ})$; radiation of coldest quarter (RCQ); annual mean moisture index (AMI); mean moisture index of the highest quarter (MHQ); mean moisture index of lowest quarter (MeMILQ); mean moisture index of the warmest quarter (MMIWaQ); mean moisture index of the coldest quarter (MMICQ); and moisture index seasonality $\mathrm{C} / \mathrm{V}$ (MIS). Geographic positions of latitude and longitude were used as variables in analyses along with altitude (elevation above sea level in metres), physiography (crest to open 
depression; scored 1 to 6), soil depth (deep to skeletal; scored 1 to 3), drainage (waterlogged to well drained; scored 1 to 4) original plot size (all of which were measured in the field), and stem plot evenness. Thus a total of 43 variables were calculated or scored for each site.

2.4. Statistical Analyses. Species data was presented in the form of a matrix of species by sites. The first matrix was populated by the AGB of each individual. Three additional matrices were created where the AGB was based on the size of the original plot, the original plot scaled to one hectare based on the furthest stem from the centre, and the original plot scaled to one hectare using the average distance to all stems from the central tree. "Environmental" data was presented as a matrix of factors by sites. The CANOCO5 package [27] was used to test the effects of physical, locational, and climatic variables on the unscaled AGB data and the two datasets scaled to one hectare. This was done in order to test the robustness of results and to quantify the effect of scaling to one hectare. As the response data is compositional and the gradient lengths were 9.4 SD units long, unimodal canonical correspondence analysis (CCA) was considered the most appropriate analysis technique by the advisor module within CANOCO5. Significant environmental variables were chosen by the manual forward selection procedure in CANOCO5, followed by Monte Carlo permutation tests (1000 iterations). Forward selection allows for the removal of collinear/redundant variables from the regression model and subsequent reanalysis of the contribution of the remaining unselected variables as each new variable is added to the model. Holm's correction was used in order to adjust the significance values for potential inflated family-wise type I errors, thus reducing the chances of colinearity and false significance [27]. Only variables which achieved a $P$ value of less than 0.05 after Holm's correction were included within the model.

The effect of significant variables on AGB was tested using regression modelling. Generalised additive modelling (GAM) was used to model the single attribute of AGB against the constrained ordination space. GAM models of differing model complexity starting with the null model through differing degrees of freedom were generated. The GAM model with highest parsimony was tested via Akaike Information Criterion. Simple linear regression was also performed on AGB and specific gravity per plot to test conceptual models of the contribution of larger diameter trees and changes in wood density across the environmental gradient sampled. The evenness of plots was also regressed against AGB and specific gravity to test if there may have been significant effect of differences in dispersion on the results obtained.

\section{Results}

A total of 197 species were identified over $10 \mathrm{~cm} \mathrm{DBH}$ within sites and 36,334 individuals were measured for diameter, height, and dispersion. The most abundant genera were Eucalyptus and Acacia which accounted for 67 and 27 species, respectively.

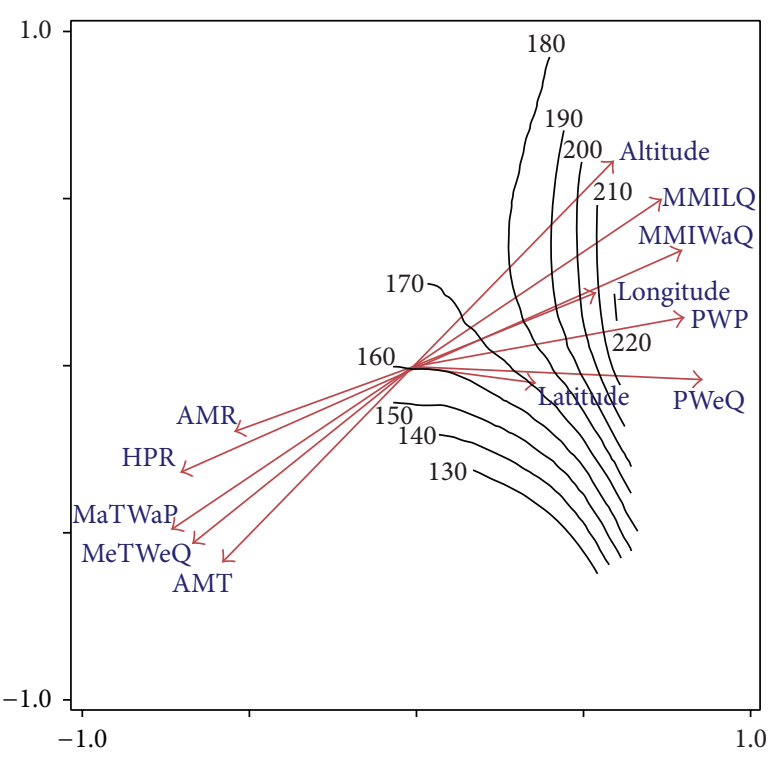

FIGURE 2: Generalised additive model based contour plot for AGB per plot against the 12 most significant environmental variables (minimum of $0.3 \%$ explained variance) within the CCA model. Codes given in Table 1 . Axes are the first two axes of the CCA analysis.

There was no significant effect of evenness on AGB or specific gravity, at each site across the dataset. There was a high degree of congruence between the CCA results for the scaled and unscaled AGB datasets. Within the scaled dataset original plot size was added as a variable and found to be nonsignificant. Evenness (test of clumping) also did not appear as a significant variable in any of the analyses. The nonsignificance of plot size and evenness are likely due to the size and extent of the dataset which significantly downweights the influence of differences in clumping of trees across sites. Thus it was considered that the scaled to one hectare analysis could be used without undue influence of scaling error. Thirty-six of the 43 environmental variables were found to be of significance after Holms correction $(P \leq 0.05)$ in relation to variation in AGB (Figure 2). These 36 significant variables accounted for $11.7 \%$ of the total inertia of the scaled dataset. The first two axes of the CCA model explained $22.7 \%$ of the variance within the dataset. MaTWaP and PWP (seasonal summer attributes) were of greatest explanatory power for AGB within the dataset (Table 1). The explained variation in AGB was directly explored using GAM (Figure 2). Overall the 12 variables with greatest explanatory power (as assessed by the arbitrary cut-off point of $0.3 \%$ explained variance; Table 1) indicate that an increase in moisture within the soil (MMILQ, MMIWaQ), greater precipitation (PWP, AMR), higher altitudes but lower radiation (AMR, HPR), and lower temperatures (AMT, MaTWaP, and MeTWeQ) are associated with an increase in AGB (Table 1; Figure 2).

Despite the incorporation of a significant number of climatic variables the spatial variables of latitude, longitude, and altitude were found to be of significance. These spatial variables are accounting for unmeasured environmental 
TABLE 1: Codes and descriptions of significant variables $(P \leq 5 \%)$ listed in order of decreasing importance (contribution) from forward selection in canonical correspondence analysis.

\begin{tabular}{|c|c|c|c|c|}
\hline Code & Name (direction of influence) & $\%$ contribution & $\%$ explained & $P($ adj $)$ \\
\hline MaTWaP & Max temperature of warmest period (-ve) & 10.3 & 1.0 & $<0.05$ \\
\hline PWP & Precipitation of wettest period (+ve) & 8.0 & 0.8 & $<0.05$ \\
\hline MeTWaQ & Mean temperature of warmest quarter $(-\mathrm{ve})$ & 5.6 & 0.5 & $<0.05$ \\
\hline MeMILQ & Mean moisture index of low quarter (+ve) & 5.5 & 0.5 & $<0.05$ \\
\hline Latitude & Latitude $(+\mathrm{ve})$ & 4.8 & 0.5 & $<0.05$ \\
\hline AMR & Annual mean radiation $(-\mathrm{ve})$ & 4.5 & 0.4 & $<0.05$ \\
\hline MMIWaQ & Mean moisture index of warmest quarter (+ve) & 2.9 & 0.3 & $<0.05$ \\
\hline Longitude & Longitude $(+\mathrm{ve})$ & 2.9 & 0.3 & $<0.05$ \\
\hline PWeQ & Precipitation of wettest quarter (+ve) & 3.1 & 0.3 & $<0.05$ \\
\hline AMT & Annual mean temperature (-ve) & 3.1 & 0.3 & $<0.05$ \\
\hline HPR & Highest period radiation (-ve) & 2.8 & 0.3 & $<0.05$ \\
\hline Alt & Altitude (+ve) & 2.9 & 0.3 & $<0.05$ \\
\hline PCQ & Precipitation of coldest quarter (+ve) & 2.6 & 0.2 & $<0.05$ \\
\hline PS & Precipitation seasonality (+ve) & 2.6 & 0.2 & $<0.05$ \\
\hline LPR & Lowest period radiation (+ve) & 2.4 & 0.2 & $<0.05$ \\
\hline Physiography & Physiography $(-\mathrm{ve})$ & 2.4 & 0.2 & $<0.05$ \\
\hline MIS & Moisture index seasonality (-ve) & 2.1 & 0.2 & $<0.05$ \\
\hline MMICQ & Mean moisture index of cold quarter (+ve) & 2.5 & 0.2 & $<0.05$ \\
\hline MDR & Mean diurnal range $(-\mathrm{ve})$ & 2.2 & 0.2 & $<0.05$ \\
\hline Drainage & Drainage $(-$ ve $)$ & 2.0 & 0.2 & $<0.05$ \\
\hline HPMI & Highest period moisture index (+ve) & 1.7 & 0.2 & $<0.05$ \\
\hline TAR & Temperature annual range (-ve) & 1.8 & 0.2 & $<0.05$ \\
\hline PDP & Precipitation of driest period (+ve) & 1.8 & 0.2 & $<0.05$ \\
\hline $\mathrm{AP}$ & Annual precipitation (+ve) & 1.8 & 0.2 & $<0.05$ \\
\hline RS & Radiation seasonality (-ve) & 1.7 & 0.2 & $<0.05$ \\
\hline LPMI & Lowest period moisture index (+ve) & 1.5 & 0.1 & $<0.05$ \\
\hline RCQ & Radiation of coldest quarter (+ve) & 1.4 & 0.1 & $<0.05$ \\
\hline MTCQ & Mean temperature of coldest quarter (-ve) & 1.3 & 0.1 & $<0.05$ \\
\hline RWQ & Radiation of wettest quarter (-ve) & 1.2 & 0.1 & $<0.05$ \\
\hline MeTWeQ & Mean temperature of wettest quarter (-ve) & 1.4 & 0.1 & $<0.05$ \\
\hline PDQ & Precipitation of driest quarter (+ve) & 1.1 & 0.1 & $<0.05$ \\
\hline AMMI & Annual mean moisture index (+ve) & 1.0 & $<0.1$ & $<0.05$ \\
\hline MeMIHQ & Mean moisture index of high quarter (+ve) & 1.0 & $<0.1$ & $<0.05$ \\
\hline Isothermality & Isothermality $(+\mathrm{ve})$ & 1.0 & $<0.1$ & $<0.05$ \\
\hline RWaQ & Radiation of warmest quarter (-ve) & 0.9 & $<0.1$ & $<0.05$ \\
\hline PWaQ & Precipitation of warmest quarter (+ve) & 0.9 & $<0.1$ & $<0.05$ \\
\hline
\end{tabular}

attributes. Two significant variables of minor explanatory power were site physical characteristics (physiography and drainage). There is a slight positive relationship between physiography and drainage variables indicating greater AGB at lower topographic positions but on well drained sites.

Simple linear regression showed a relationship (14.5\% of variance) between the AGB of the largest stem within a site and the AGB of the entire site (Figure 3). Allometric traits are known to be phylogenetically conservative [2]; therefore some additional graphical and regression techniques have been applied. A negative relationship (29\% of variance) between the average SpecGrav (wood density) for all Eucalyptus and altitude exists (Figure 4). Linear regression was performed on average Eucalyptus height records for each site excluding all other genera to control for phylogeny (Figure 5). In addition the most abundantly recorded Myrtaceae taxa that occurred across the greatest altitudinal range were regressed against altitude (Figure 5). Overall there is an increase in the height of Eucalyptus species with increasing altitude. In contrast, there is a slight negative relationship between the heights of widespread individual species across the altitudinal gradient (Figure 5).

The proportional distribution of AGB across major taxonomic groups and altitude is shown in Figure 6. Partitioning the contribution of major taxonomic groups shows clearly that there is a change in the dominance of broad 


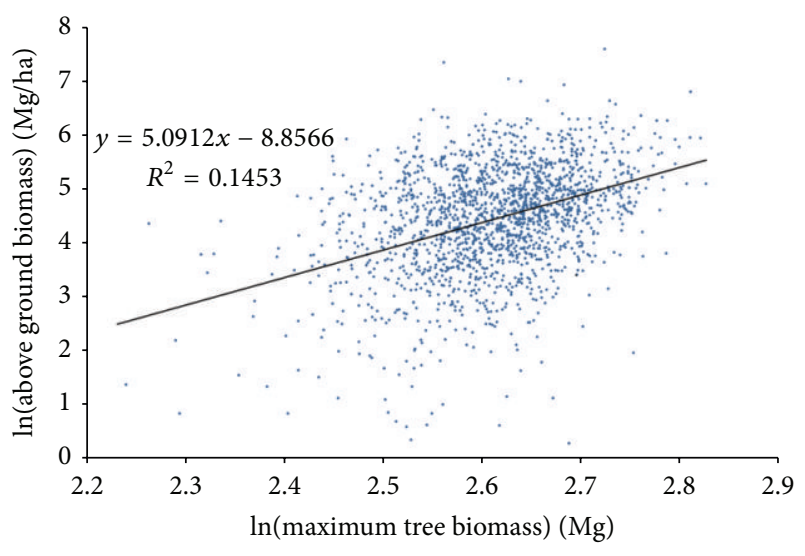

FIGURE 3: Contribution of the above ground biomass (AGB) of the largest tree per plot and the total AGB of the plot.

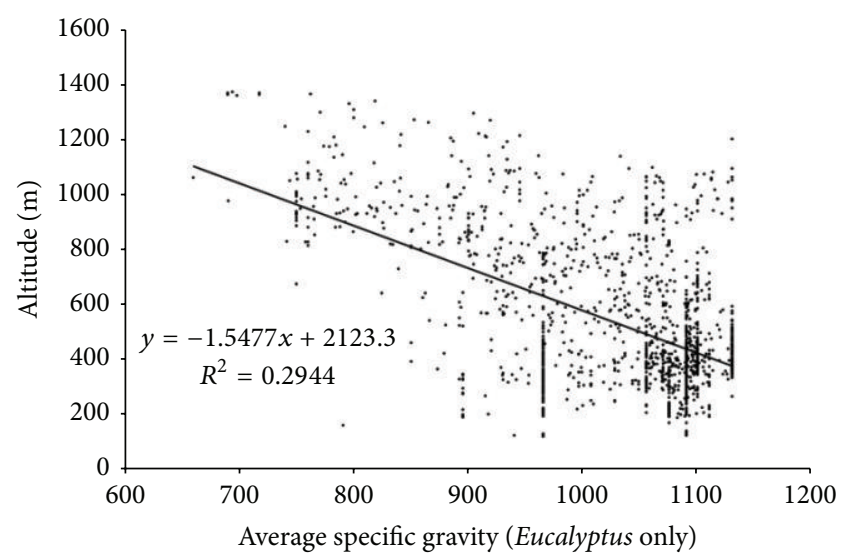

FIGURE 4: Correlation in the average specific gravity of all Eucalyptus for each plot against altitude.

taxonomic groups over the altitudinal gradient. Softwood species (Cupressaceae: Callitris endlicheri and C. glaucophylla) provide approximately $30 \%$ of the total AGB between 400 and $800 \mathrm{~m}$ altitude. Fabaceae (primarily Acacia) is most important in terms of AGB at lowest altitudes $(<800 \mathrm{~m})$. Eucalyptus, though prevalent across all altitudinal zones, accounts for $80 \%$ of all the AGB with Callitris accounting almost no AGB at the highest altitudes [28]. The importance of Callitris also decreases at the lowest altitudes with an increase in both Eucalyptus and Casuarinaceae (Allocasuarina and Casuarina). The increase in the prominence of Casuarinaceae is due to the prominence of Allocasuarina luehmannii and Casuarina cristata at lower altitudes. Rutaceae are of minor prominence within the region at lower altitudes and are replaced by Proteaceae at higher altitudes. The results potentially indicate greater taxonomic diversity within the overstorey within the mid altitudes and a weakening of the biomass dominance of Eucalyptus within this zone.

\section{Discussion}

Latitude, longitude, and altitude were all found to be of significance in the CCA model explaining variance in select allometric traits (Figure 2). Despite 15 climatic and two physical variables being of significance in the CCA model it is obvious that there were still unmeasured traits that covary with these spatial variables. It is difficult to predict what these might be; in relation to altitude they could include a reduction in photosynthesis due to the decrease in atmospheric pressure [10]. As the dividing range runs southwest the combination of latitude and longitude would be acting along this geographic feature. It is unknown what latitude and longitude may account for, though the angle at which solar radiation occurs would vary along a latitudinal gradient. Latitude has featured as a significant variable in angiosperm wood traits in a number of investigations in a wide variety of communities and locations $[2,19,29]$.

AGB was primarily correlated with an increase in moisture availability, particularly during the driest period and with an increase in the moisture index (Figures 2 and 3 ). Higher mean moisture index values indicate a surplus of water (precipitation minus evaporation) available for retention in the landscape. However annual mean rainfall was not found to be a significant factor in the CCA model potentially indicating that the amount of rainfall is less informative than when that rainfall occurs and how much is retained after evaporation. Although AGB was negatively correlated to the annual mean radiation (AMRad), the highest AMRad is associated with the most northerly and western locations which are the driest. AGB was largely unresponsive to changes in temperature and other measures of radiation. Although higher temperatures were uninformative, lower temperatures are correlated with some increase in AGB (Figure 3). These results are in agreement with a number of investigations that have shown moisture availability to be a better predictor than temperature and solar radiation in drier climates [3, 11,30-32]. The results also concur with Keith et al. [13] and Culmsee et al. [9] who found biomass to peak in cool wet environments but do not match those of Banin et al. [3]. The system investigated here is a temperate one rather than tropical and moisture may be retained during dry seasons due to an increase in the covariables associated with increasing moisture index. Overall AGB was highest where moisture was available all year round (+ve to PDQ, PDP, PWP, HPMI, and MMILQ) either through direct rainfall and/or water retention in the landscape. These results are more akin to the results of Slik et al. [11] who suggested that stable wet climates were important for accumulation of AGB. Current climate change scenarios for the region predict that, while mean annual rainfall may not diminish significantly seasonality of rainfall will increase along with a reduction in the mean moisture index [33]. This will lead to a reduction in AGB and therefore reduce the ability of these forests and woodlands to store carbon.

It is logical to assume a relationship between wood density and the number of stems as both scores are used to calculate AGB (see Section 2), though Stegen et al. [7] have shown that this is not a consistent rule across spatial scales 


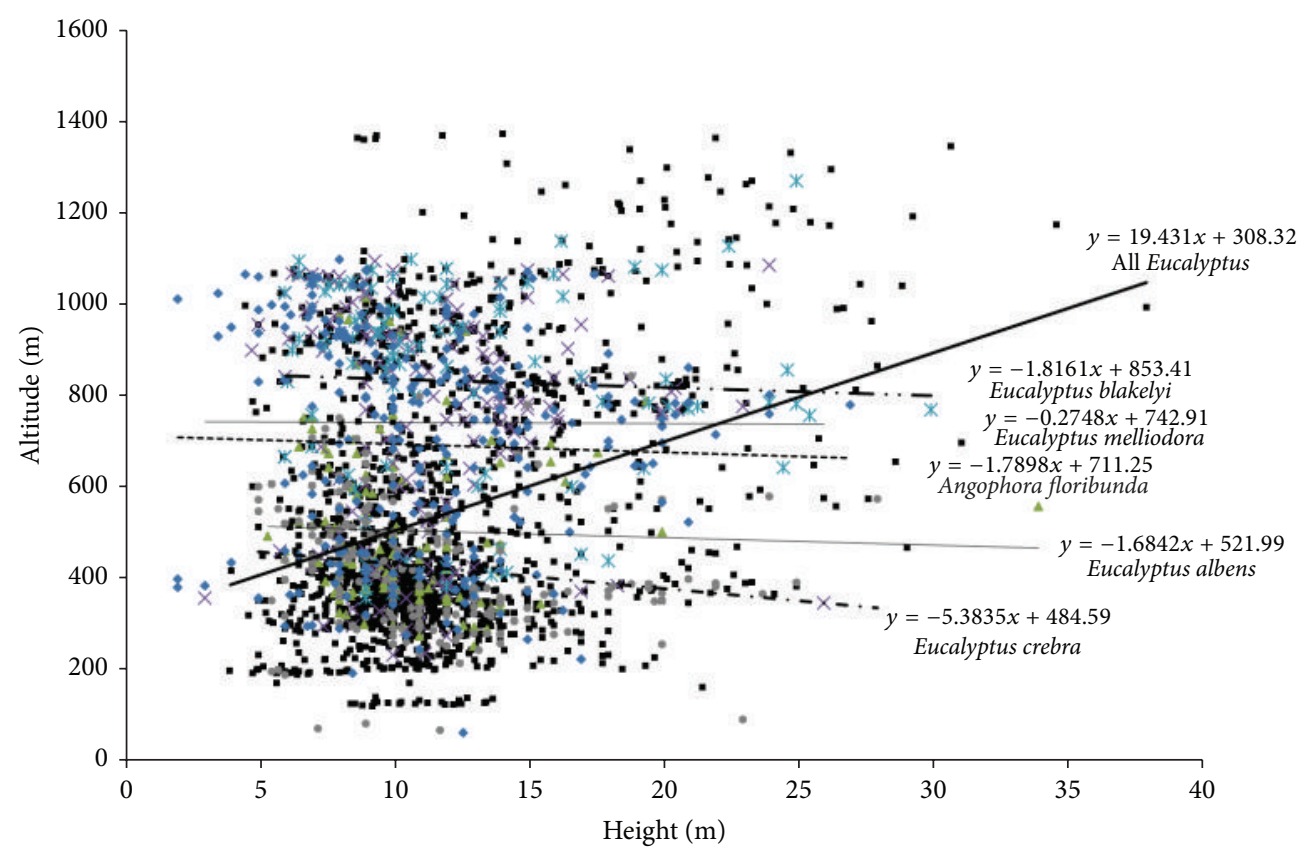

FIGURE 5: Change in average tree height of all Eucalyptus species within site (interspecific variation) and the average height of five selected widespread species (intraspecific variation) against the altitude gradient. Note there is a small negative change in the average tree heights of individual species with increasing altitude. Overall there is an increase in the height of the summed Eucalyptus scores for each site.

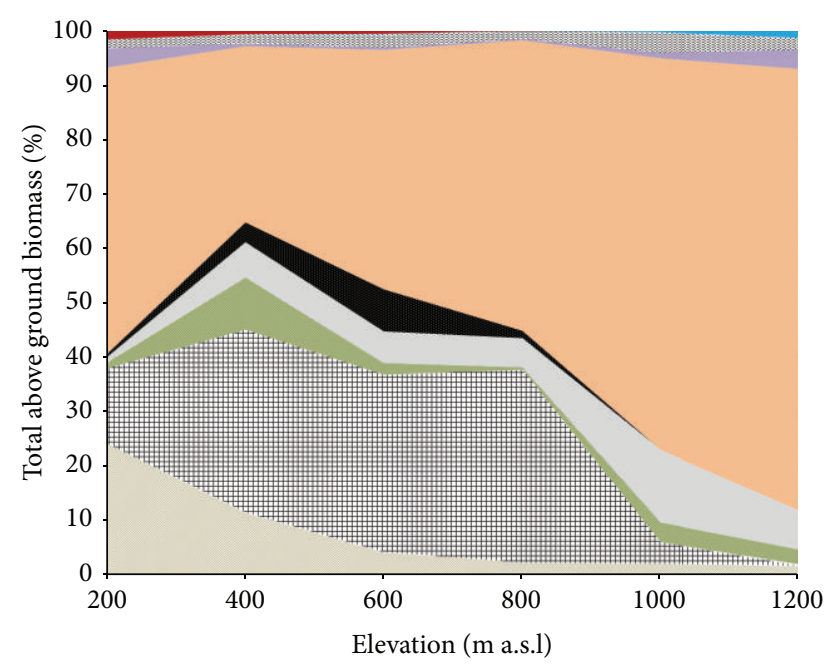

$\begin{array}{ll}\text { Rutaceae } & \mathbf{8} \text { Myrtaceae: Corymbia } \\ \text { Proteaceae } & \text { Myrtaceae: Angophora } \\ \text { Other } & \text { Fabaceae } \\ \begin{array}{l}\text { Myrtaceae: other } \\ \text { Myrtaceae: Eucalyptus }\end{array} & \# \text { Cupressaceae } \\ & \% \text { Casuarinaceae }\end{array}$

FIGURE 6: Variation in the contribution of major taxonomic groups to above ground biomass (AGB) across an altitudinal gradient in eastern Australia.

or different forest types. Through similar reasoning it can be assumed that height and diameter should correlate strongly with AGB due to their importance in the calculations; this was not the case here. Therefore, at least in this region the number of stems and the density of wood (specific gravity) are of primary importance to overall AGB. Further analysis by linear regression of the biomass of the largest tree against the total site biomass showed a small but significant positive relationship (explaining $14.5 \%$ of the variance). As discussed by Midgley et al. [14] it is expected that a negative relationship would result if competition was limiting AGB and that a positive relationship signifies that competition is weak. Though only $14.5 \%$ of the variance in overall AGB is explained by the AGB of the largest stem there is some support for the species packing hypothesis and weak competition.

Stegen et al. [7] suggested that disturbance and the temporal trends associated with recovery can decouple the importance of tree size and tree density relationships with AGB. Niklas et al. [34] also argued that disturbance rates were important in determining maximum plant size and that disturbance, not competition, had a central role in determining community basal area and how biomass accumulates. It is possible that the lack of disturbances or the type of those disturbances and the ability of the species to cope with these disturbances have increased the link between AGB and the density of stems and wood density. The most prevalent landscape level disturbances within the study region are fire and drought. Fire and drought are disturbance events that cause disproportional mortality by removing both larger stems and the youngest individuals; both events are independent of resource availability and competition. Thus, independently fire and drought are likely to promote intermediate sized stems and, depending on frequency and severity, to decouple competitive interactions between size classes $[35,36]$. Hence, fire and drought may diminish the importance of height and 
diameter in calculations of AGB and reduce the correlation between the largest stem and site AGB. Evidence suggests that interactions of fire and drought may cause synergistically greater disturbance within the study region exacerbating effects on species $[37,38]$. It is predicted that within the region there will be an increase in the regularity and severity of drought and fire [33]. Though not part of this study it would be worth investigating how wood density and AGB vary across communities that experience different fire frequencies.

Many allometric properties are phylogenetically conservative $[2,3,6,17,25]$. Thus, it is necessary to view the taxonomic distribution of the values obtained in order to control for this confounding factor. Partitioning the contribution of major taxonomic groups shows clearly that there is a change in the dominance of broad taxonomic groups over the altitudinal gradient (Figure 6). Softwood species provide approximately a significant component of the total AGB between 400 and $800 \mathrm{~m}$ altitude largely at the expense of Eucalyptus ([28], Figure 6). The increasing prevalence of Eucalyptus and the decrease in the prominence of Callitris could account for much of the increase in AGB with altitude. Similarly Eucalyptus generally have greater stem widths and height than Callitris and Allocasuarina; this disparity may also account for the decline in height and stem widths with decreasing altitude. To remove this potential confounding factor Eucalyptus was isolated for analysis but still showed the same overall patterns with increasing altitude. The average wood density (specific gravity) of Eucalyptus stems decreases with increasing altitude (Figure 4) indicating that these correlations are not simply an artefact of increased prevalence of softwood species at lower altitudes and therefore not due to phylogeny. This result suggests that lower altitudes sites (lower rainfall and moisture index and increased temperatures and radiation) favour Eucalyptus species with higher wood density (specific gravity). Higher altitudes sites (increased rainfall and mean moisture index, lower temperatures, and radiation) favour species with lower wood densities (specific gravity).

There is an increase in the height of all Eucalyptus stems (interspecies comparison) with increasing altitude (Figure 5). This was not found during intraspecies comparisons of the most widespread taxa (Figure 5). Within individual species that occurred across a wide range of altitudes there was a very slight decrease in height with increasing altitude across all examined in contrast to the overall pattern of increased average height within stands. Within Eucalyptus, species with lower wood density and taller growth habits are favoured at higher altitudes (wetter and cooler) while shorter species with higher wood density are favoured at lower altitudes (drier and hotter). This supports the findings of Slik et al. [11] who showed that drought disproportionately increased the mortality of large trees with low wood densities and also supports the hydraulic limitation hypothesis $[3,4]$. The results are also in agreement with those presented by Lines et al. [4] who showed that landscape level trends in observed tree heights and other allometric properties were primarily a result of changing species composition along gradients rather than changes within species. Species show comparatively little adaptability in their allometric characteristics with changes in climate conditions $[4,21]$. Species have a poor capacity to adapt to predicted climate change and a change in composition is the most likely outcome in the short term.

\section{Conclusion}

AGB increases in wetter and cooler locations. This increase is related to the amelioration of seasonal rainfall deficits that occur in this summer dominant rainfall zone. Taller and greater diameter trees with lower wood densities occur at higher altitudes. These changes in AGB, though not linked to phylogeny, are based on a change in the composition of species rather than a change in the allometric properties within a species. The data supports the hydraulic limitation hypothesis and provides some evidence for species packing. $\mathrm{AGB}$ at a site is associated closely with an increase in the density of stems at a site and the average wood density of trees and less so by the influence of the largest tree and average stem height and diameter. Within this region these interrelationships are likely affected by interactions with fire frequency. Fire is a common feature of much of the study area; fire frequency and related variables require further investigation in this context. Both drought and fire are likely to become more frequent and severe with climate change. Drought will increasingly become the most limiting factor within the region and thus, singularly and in combination with fire, will drive changes in allometric properties and subsequently species interactions. Based on the evidence provided in this investigation significant changes in species composition and the distribution of allometric traits will occur across the landscape with changing climate. These changes will include a reduction in above ground biomass, the number of stems per hectare, the average height, average diameter, and basal area. The largest of trees are likely to be removed early due to their inability to cope with increased drought stress. A flow on of these affects will be a marked reduction in carbon storage across north eastern Australia.

\section{Conflict of Interests}

The author declares that there is no conflict of interests regarding the publication of this paper.

\section{Acknowledgments}

Though the inventory was collected by the author I wish to thank the following who helped with measurements at various times over the six years; Daniel Bailey, Dorothy Bell, Gary Chorley, Peter Croft, Sean Forde, Rachael Gleeson, Briannon Growns, Zak Growns, Darren Hall, Stephen Hammond, Wendy Hawes, Alan Hill, Calliden Hunter, Vanessa Hunter, Peter Jobson, Jason Kreis, Michael Leiberman, Alex Pawlow, Kate Smillie, Jessica Stokes, and Duncan Vennell. No funding was provided for this research and it was conducted purely on the author's interest and time. 


\section{References}

[1] S. Lavorel and E. Garnier, "Predicting changes in community composition and ecosystem functioning from plant traits: revisiting the Holy Grail," Functional Ecology, vol. 16, no. 5, pp. 545-556, 2002.

[2] S.-B. Zhang, J. W. F. Slik, J.-L. Zhang, and K.-F. Cao, "Spatial patterns of wood traits in China are controlled by phylogeny and the environment," Global Ecology and Biogeography, vol. 20, no. 2, pp. 241-250, 2011.

[3] L. Banin, T. R. Feldpausch, O. L. Phillips et al., "What controls tropical forest architecture? Testing environmental, structural and floristic drivers," Global Ecology and Biogeography, vol. 21, no. 12, pp. 1179-1190, 2012.

[4] E. R. Lines, M. A. Zavala, D. W. Purves, and D. A. Coomes, "Predictable changes in aboveground allometry of trees along gradients of temperature, aridity and competition," Global Ecology and Biogeography, vol. 21, no. 10, pp. 1017-1028, 2012.

[5] M. Aiba and T. Nakashizuka, "Architectural differences associated with adult stature and wood density in 30 temperate tree species," Functional Ecology, vol. 23, no. 2, pp. 265-273, 2009.

[6] J. C. Stegen, N. G. Swenson, B. J. Enquist et al., "Variation in above-ground forest biomass across broad climatic gradients," Global Ecology and Biogeography, vol. 20, no. 5, pp. 744-754, 2011.

[7] J. C. Stegen, N. G. Swenson, R. Valencia, B. J. Enquist, and J. Thompson, "Above-ground forest biomass is not consistently related to wood density in tropical forests," Global Ecology and Biogeography, vol. 18, no. 5, pp. 617-625, 2009.

[8] M. Larjavaara and H. C. Muller-Landau, "Temperature explains global variation in biomass among humid old-growth forests," Global Ecology and Biogeography, vol. 21, no. 10, pp. 998-1006, 2012.

[9] H. Culmsee, C. Leuschner, G. Moser, and R. Pitopang, "Forest aboveground biomass along an elevational transect in Sulawesi, Indonesia, and the role of Fagaceae in tropical montane rain forests," Journal of Biogeography, vol. 37, no. 5, pp. 960-974, 2010.

[10] J. Gale, "Availability of carbon-dioxide for photosynthesis at high-altitudes-theoretical considerations," Ecology, vol. 53, no. 3, pp. 494-497, 1972.

[11] J. W. F. Slik, S.-I. Aiba, F. Q. Brearley et al., "Environmental correlates of tree biomass, basal area, wood specific gravity and stem density gradients in Borneo's tropical forests," Global Ecology and Biogeography, vol. 19, no. 1, pp. 50-60, 2010.

[12] S. S. Saatchi, R. A. Houghton, R. C. dos Santos Alvalá, J. V. Soares, and Y. Yu, "Distribution of aboveground live biomass in the Amazon basin," Global Change Biology, vol. 13, no. 4, pp. 816-837, 2007.

[13] H. Keith, B. G. Mackey, and D. B. Lindenmayer, "Reevaluation of forest biomass carbon stocks and lessons from the world's most carbon-dense forests," Proceedings of the National Academy of Sciences of the United States of America, vol. 106, no. 28, pp. 11635-11640, 2009.

[14] J. J. Midgley, R. Parker, H. Laurie, and A. Seydack, "Competition among canopy trees in indigenous forests: an analysis of the 'additive basal area' phenomenon," Austral Ecology, vol. 27, no. 3, pp. 269-272, 2002.

[15] M. J. Lawes, J. J. Midgley, S. Boudreau, and M. E. Griffiths, "Lack of disturbance as an explanation for the additive basal area phenomenon in a stratified Afrotemperate forest," Austral Ecology, vol. 31, no. 4, pp. 471-477, 2006.
[16] H. C. Muller-Landau, R. S. Condit, J. Chave et al., “Testing metabolic ecology theory for allometric scaling of tree size, growth and mortality in tropical forests," Ecology Letters, vol. 9, no. 5, pp. 575-588, 2006.

[17] T. R. Baker, O. L. Phillips, Y. Malhi et al., "Variation in wood density determines spatial patterns in Amazonian forest biomass," Global Change Biology, vol. 10, no. 5, pp. 545-562, 2004.

[18] J. Chave, C. Andalo, S. Brown et al., "Tree allometry and improved estimation of carbon stocks and balance in tropical forests," Oecologia, vol. 145, no. 1, pp. 87-99, 2005.

[19] J. Chave, H. C. Muller-Landau, T. R. Baker, T. A. Easdale, T. E. R. H. Steege, and C. O. Webb, "Regional and phylogenetic variation of wood density across 2456 neotropical tree species," Ecological Applications, vol. 16, no. 6, pp. 2356-2367, 2006.

[20] O. O. Osunkoya, T. K. Sheng, N.-A. Mahmud, and N. Damit, "Variation in wood density, wood water content, stem growth and mortality among twenty-seven tree species in a tropical rainforest on Borneo Island," Austral Ecology, vol. 32, no. 2, pp. 191-201, 2007.

[21] H. D. Adams and T. E. Kolb, "Tree growth response to drought and temperature in a mountain landscape in northern Arizona, USA," Journal of Biogeography, vol. 32, no. 9, pp. 1629-1640, 2005.

[22] R. Thackway and I. D. Cresswell, An Interim Biogeographic Regionalisation for Australia: A Framework for Setting Priorities in the National Reserves System Cooperative Program, Version 4.0, Australian Nature Conservation Agency, Canberra, Australia, 1995.

[23] Ø. Hammer, D. A. T. Harper, and P. D. Ryan, "Past: Paleontological statistics software package for education and data analysis," Palaeontologia Electronica, vol. 4, article 9, 2001.

[24] D. J. Boland, M. I. H. Brooker, G. M. Chippendale et al., Forest Trees of Australia, Nelson-CSIRO, Canberra, Australia, 1984.

[25] J. W. F. Slik, "Estimating species-specific wood density from the genus average in Indonesian trees," Journal of Tropical Ecology, vol. 22, no. 4, pp. 481-482, 2006.

[26] T. Xu and M. Hutchinson, ANUCLIM 6.1, Australian National University, Canberra, Australia, 2011.

[27] C. J. F. ter Braak and P. Šmilauer, CANOCO Reference Manual and User's Guide: Software for Ordination (Version 5.0), Microcomputer Power, Ithaca, NY, USA, 2012.

[28] J. T. Hunter, "Interactions between Callitris above-ground biomass, species density and plant form in north-eastern New South Wales," Australian Journal of Botany, vol. 61, no. 1, pp. 7379, 2013.

[29] N. G. Swenson and B. J. Enquist, "Ecological and evolutionary determinants of a key plant functional trait: wood density and its community-wide variation across latitude and elevation," American Journal of Botany, vol. 94, no. 3, pp. 451-459, 2007.

[30] H. I. Martínez-Cabrera, C. S. Jones, S. Espino, and H. Jochen Schenk, "Wood anatomy and wood density in shrubs: responses to varying aridity along transcontinental transects," American Journal of Botany, vol. 96, no. 8, pp. 1388-1398, 2009.

[31] J. T. Hunter and D. M. Bell, "Season and timing of moisture availability predict composition of montane shrub-dominated wetlands at distributional limits in eastern Australia," Australian Journal of Botany, vol. 61, no. 4, pp. 243-253, 2013.

[32] J. T. Hunter, "Seasonality of climate drives the number of tree hollows in eastern Australia: implications of a changing climate," International Journal of Ecology, vol. 2015, Article ID 190637, 10 pages, 2015. 
[33] K. Hennessy, C. Page, K. McInnes, R. Jones, and A. Bathols, Climate Change in New South Wales. Part 1: Past Climate Variability and Projected Changes in Average Climate, CSIRO, Australian Government Bureau of Meteorology, Canberra, Australia, 2004.

[34] K. J. Niklas, J. J. Midgley, and R. H. Rand, "Tree size frequency distributions, plant density, age and community disturbance," Ecology Letters, vol. 6, no. 5, pp. 405-411, 2003.

[35] J. C. Z. Woinarski, H. F. Recher, and J. D. Majer, "Vertebrates of eucalypt formations," in Eucalypt Ecology: Individuals to Ecosystems, J. E. Williams and J. C. Z. Woinarski, Eds., Cambridge University Press, Cambridge, UK, 1997.

[36] J. Courtney and S. J. S. Debus, "Breeding habits and conservation status of the Musk lorikeet Glossopsitta concinna and Little Lorikeet G. pusilla in northern New South Wales," Australian Field Ornithology, vol. 23, pp. 109-124, 2006.

[37] P. Croft, J. T. Hunter, and N. Reid, "Depletion of regenerative bud resources during cyclic drought: what are the implications for fire management?" Ecological Management \& Restoration, vol. 8, no. 3, pp. 187-192, 2007.

[38] P. Croft, J. T. Hunter, and N. Reid, "Threat of frequent fire and drought for the rare wattle Acacia williamsiana J. T. Hunter: an experimental burn highlights implications for fire management," Ecological Management and Restoration, vol. 11, no. 3, pp. 217-220, 2010. 

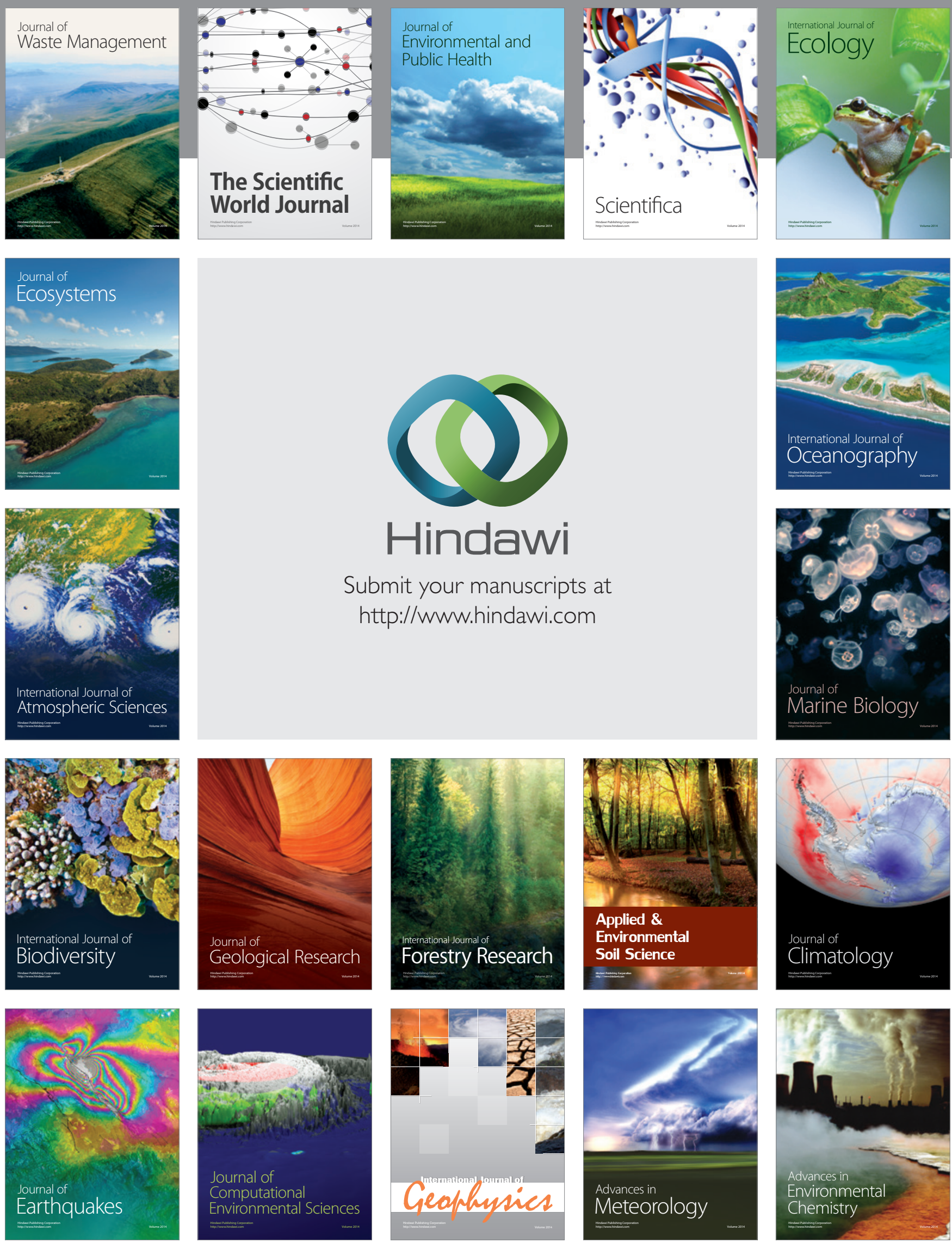